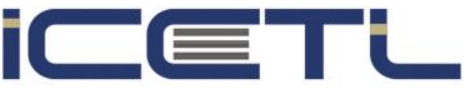

21-23 FEBRUARY, 2020

\title{
Bringing Neuroscience to Education: Using an Innovative Method - The "BRAIN" Method - For Teaching Human Motor Control in Higher Education Students
}

\author{
Hugo Santos ${ }^{1}$, Elisabete Martins ${ }^{2}$, Isabel Baleia ${ }^{3}$ \\ ${ }^{1}$ Alcoitão School of Health Science
}

\begin{abstract}
The past decade has seen a tremendous interest in the potential of applying insights from neuroscience to educational settings. Some refer to this emerging field of translational research as 'neuroeducation', others call it: 'mind, brain and education' or 'educational neuroscience'. After a review of the literature on neuroeducation we created a method based on and combined the most cited principles: Priming; Constructivism; Feedback; Motivation; Reward; Cooperative work and Self-assessment. So we created the method BRAIN, wich means - BRing what you know / Acquire new knowledge / Inquiring about what you have learned / aNalyze what you have learned. We use this method in the motor control course of the physiotherapy course of our school. The themes were distributed by modules of 2 classes (one theoretical and one practical) and each module was planned taking into account the BRAIN model. For the lectures, small preparatory activities were built to activate students' prior knowledge and prepare them for the class. During the classes the contents were presented by the teacher through a combination of expository method with interactive methods. For practical classes, activities were performed in small groups. For all modules the learning objectives were divided into 3 levels, basic, advanced and advanced + . Out of class students performed consolidation activities that gave them bonus points. During the course 2 written tests and an oral test were applied. We applied a satisfaction questionnaire and made a focus group to know the opinion of the students on the subject. After analyzing the questionnaire and the focal group we can conclude that the students were very satisfied with the implemented methodology. Regarding the grades, the performance of the class reached a very good level.
\end{abstract}

Keywords: Active learning; Inquiring; Motivation; Neuroeducation; Priming 